\title{
La cultura organizacional, su importancia en el desarrollo de las empresas
}

\section{The organizational culture, its importance in the development of companies}

\author{
María Auxiliadora Guerrero Bejarano, MBA \\ Universidad Internacional del Ecuador, Ecuador \\ Daniel Ricardo Silva Siu, MSc \\ Universidad ESAN, Perú
}

Autor para correspondencia: maguerrerobe@uide.edu.ec, dsilva@pobox.com

Fecha de recepción: 5 de enero de 2017 - Fecha de aceptación: 20 de Febrero de 2017

\section{Resumen}

En el mercado actual, en el que mantenerse, desarrollarse e ir pasando de una etapa de vida a otra, dentro del ciclo de vida de los negocios, resulta cada vez más complejo, se analizan las diferentes razones por la que unas organizaciones obtienen mejores resultados que otras; desde hace algunas décadas los académicos y profesionales han volcado su atención en el recurso humano como un factor importante para la consecución de los objetivos trazados por las empresas. Este análisis teórico busca entender la cultura organizacional como uno de los factores que podría incidir en el desarrollo de las empresas.

Palabras claves: negocios; organizaciones; desarrollo empresarial

\begin{abstract}
In the current market, in which to keep, develop and move from one stage of life to another, within the business life cycle, is increasingly complex, we analyze the different reasons why some organizations obtain better results what others; for some decades academics and practicioner have turned their attention to the human resource as an important factor for the achievement of the goals set by the companies. This theoretical analysis seeks to understand organizational culture as one of the factors that could insinuate in the development of companies.
\end{abstract}

Key words: business; organizations; business development 


\section{Introducción}

La cultura organizacional va tomando cada vez mayor importancia en la investigación del comportamiento de las organizaciones y los resultados obtenidos por las mismas (Ruiz \& Naranjo, 2012). De acuerdo con Porter (2006), la cultura organizacional es un factor relevante en la planificación estratégica de las organizaciones y puede permitir la diferenciación entre las empresas y la obtención de ventaja competitiva. Se define a la cultura organizacional como el conjunto de rituales y formas que comparten los miembros de una empresa y que se convierte en el descriptor del ambiente (Robbins, Judge, Millett, \& Boyle, 2013), debido a esto también sirve de guía a los nuevos empleados sobre cómo deben comportarse (Ruiz \& Naranjo, 2012). Podría ser difícil entender las culturas que rigen las distintas organizaciones, pero dada la importancia de las mismas se realizan esfuerzos para conocerlas, así como las personas que trabajan en un entorno perciben la cultura organizacional de la empresa entendiendo que esta es una predictora del clima en el que se desarrolla el trabajo (Vargas, Ruiz, \& Gracia, 2015). Este trabajo busca descubrir la importancia que la cultura podría tener en los resultados de las organizaciones. Las organizaciones tienen como objetivo fundamental la supervivencia, es decir atravesar los ciclos de vida e ir creciendo, se ha definido que las empresas tienen personalidad, necesidades y un carácter, y son consideradas pequeñas sociedades que tienen sus procesos, normas y su propia historia, todos estos factores están directamente relacionados con la cultura (González Millán \& Parra Penagos, 2008).

Cultura organizacional.- existen diferentes definiciones de cultura organizacional, algunas contradictorias (Wilkins, 1983), ha sido definida como el conjunto de creencias, valores, suposiciones y comportamientos, valores presentes en la empresa, que influyen en su desarrollo, en la formación de grupos sociales, normas, identidad que posibilita la comunicación de los miembros para la consecución de los objetivos de la empresa (Avella, 2010; Koontz, Weihrich, \& Cannice, 2008; Robbins et al., 2013; Schein, 1993, 2010; Slocum \& Hellriegel, 2009). La cultura organizacional también es definida como un patrón de comportamiento desarrollado por una empresa mientras aprende a enfrentar sus problemas de adaptación externa e integración interna; este comportamiento es aceptado como válido por todos y enseñado a los nuevos miembros (Hunger, Sánchez, Mejía, \& Hunger, 2007; Ipinza, 2008).

La cultura corporativa tiene un impacto en la identidad de la organización, el nivel de la fuerza de la cultura fomenta la participación de los miembros de la empresa, su compromiso y nivel de productividad (Denison, 1984). La cultura organizacional también influye en el aprendizaje de la organización, así como la forma en la que fluye la comunicación dentro de esta (Schein, 1993). Los emprendedores o fundadores de las empresas afectan el tipo de cultura por la fuerza de su personalidad, empezando a dar forma a la cultura del grupo, muchas veces la cultura del grupo no se desarrolla sino hasta que se han superado crisis de crecimiento y supervivencia y los equipos han desarrollado soluciones para enfrentar los factores externos (González Millán \& Parra Penagos, 2008; Schein, 1983), la cultura organizacional generalmente refleja los valores del fundador y la misión de la empresa (Hunger et al., 2007). Las culturas muestran una interpretación de la historia de la empresa, lo que es de utilidad para los empleados, esta les permite descifrar cómo se espera, se comporten en el futuro. La cultura organizacional transmite un sentido de identidad a los empleados de una organización, ayuda a generar compromiso en los empleados, aumenta la estabilidad de la organización como un sistema social y sirve como 
marco de referencia para comprender actividades organizacionales y como guía de comportamiento (Hunger et al., 2007).

Las culturas organizacionales incluyen: valores, creencias, ritos, rituales, historias, leyendas, idioma, símbolos y héroes, estos elementos son el medio para fomentarla (Robbins et al., 2013); la cultura organizacional es un factor interno que puede representar tanto una fortaleza para la organización, así como ser una debilidad que podría poner en riesgo a la misma y puede significar resistencia al cambio o ser un factor proactivo hacia el mismo (Ipinza, 2008). La cultura organizacional tiene dos características: intensidad e integración; la primera se define como el grado en el que los miembros de un departamento aceptan las normas, los valores u otro contenido cultural relacionado con el departamento, este grado de aceptación muestran la profundidad de la cultura; la segunda característica muestra el grado en el que los diferentes departamentos de una organización comparten una cultura común, lo que implica amplitud de cultura (Hunger et al., 2007). Se definen diferentes orientaciones que pueden influir en el tipo de cultura que se desarrolla en una empresa: (1) innovación y toma de riesgo, es el grado en el que se motiva a los empleados a ser innovadores y correr riesgos; (2) atención a detalles, grado en que se espera que los trabajadores sean precisos, analíticos y presten atención a los detalles; (3) orientación a los resultados, grado en que los directores se centran en los resultados obtenidos y no en las tácticas o procesos utilizados; (4) orientación a la gente, grado en que las decisiones de la alta gerencia consideran el efecto de estas sobre los colaboradores de la empresa; (5) orientación a los equipos, grado en que las actividades se organizan por equipos y no de forma individual; (6) dinamismo, grado en el que los miembros de la organización son dinámicas y competitivas en lugar de fáciles de complacer y (7) estabilidad, grado en que las actividades de la empresa estimulan el mantener el status quo en lugar de fomentar el crecimiento; estas orientaciones están presenten en todas las culturas organizacionales en distintos grados, que son evaluados para describir el tipo de cultura y su fortaleza presentes en una organización (Robbins et al., 2013; Slocum \& Hellriegel, 2009). Se plantean dos enfoques distintos para explicar el fenómeno cultural en las empresas (a) enfoque funcional que entiende la cultura como algo que tienen las instituciones, es decir una característica que puede ser observada, medida y relacionada con otra variables de la empresa, como por ejemplo rotación de personal, estilos de liderazgo, desempeño organizacional, etc; esto significa que la cultura puede ser gestionada y cambiada, siendo los directivos los encargados de dicha transformación de acuerdo con los procesos o mecanismos que determinen para el propósito y (b) el enfoque constructivista, que define que las organizaciones son entes sociales a partir de significados compartidos adquiridos mediante la interacción social, lo que significaría que las organizaciones no poseen culturas, sino que son culturas, por lo que difícilmente podrían los líderes dirigir y gestionar procesos para transformarlas o gestionarlas (Zornoza, Porta, \& García, 2009).

Se considera que las empresas pueden tener culturas débiles o culturas fuertes, las diferencias entre estos niveles de culturas radican en cuántas personas conforman una empresa, o cuánto tiempo tiene la organización funcionando, en una cultura fuerte los valores de la organización son compartidos por muchos individuos e intensamente, cuanto más miembros acepten los valores y mayor sea su compromiso hacia la empresa, más fuerte será la cultura y mayor influencia tendrá esta sobre el comportamiento de los colaboradores; en una cultura débil se presentan por ejemplo, niveles de rotación de personal más altos, el compartir los valores y creencias en una organización fomenta la cohesión, la lealtad y el compromiso organizacional, lo 
que a su vez reduce la tendencia de los empleados a abandonar la empresa (Robbins et al., 2013; Sánchez, Lanero, Yurrebaso, \& Tejero, 2007; Slocum \& Hellriegel, 2009). Las culturas también pueden ser clasificadas como tradicionales y no tradicionales, en el primer enfoque los colaboradores de una organización son vistos como factores fácilmente sustituibles y los directivos están primordialmente enfocados en los resultados que se obtienen, mientras en el enfoque no tradicional, el recurso humano tiene una mayor importancia, son considerados el recurso más importante y la empresa tiene un objetivo doble, el económico y el social, por lo que la organización estaría más preocupada por su impacto en la comunidad (Zornoza et al., 2009). Existen diferentes formas para diagnosticar la cultura de una empresa, entendiendo que la cultura organizacional puede ser gestionada, es decir que puede cambiar de acuerdo con los procesos o estrategias definidas por los directivos; se puede entonces enumerar formas como: entrevistas, estudios de documentación, análisis de contenido, diferencial semántico, técnicas de observación, reuniones de grupo y cuestionarios (Schein, 1993)

Entre los diferentes instrumentos con los que se puede medir la cultura organizacional, se encuentra el instrumento de evaluación de cultura organizacional, que evalúa seis dimensiones de la cultura, la finalidad del mismo es describir los supuestos sobre los que opera la organización, así como los valores que la caracterizan, las organizaciones son descritas por el conjunto de las diferentes respuestas obtenidas en estas dimensiones: (1) características dominantes, (2) liderazgo organizacional, (3) Gestión de los empleados, (4) pegamento organizacional, (5) énfasis estratégico y (6) criterios de éxito (Cameron \& Quinn, 2005). Seis dimensiones de contenido sirven de base para la OCAI: (1) las características dominantes de la organización, o lo que caracteriza la organización como tal; (2) el estilo de liderazgo y el enfoque que permean la organización; (3) la gestión de los empleados o el estilo que caracteriza cómo los empleados son tratados y cómo es el ambiente de trabajo; (4) el pegamento organizacional o mecanismos de unión que mantienen a la organización unida; (5) los énfasis estratégicos que definen qué áreas de énfasis impulsan la estrategia de la organización by (6) los criterios de éxito que determinan cómo se define la victoria y qué se recompensa y celebra (Cameron \& Quinn, 2005).

Existen algunos estudios que demuestran que la cultura organizacional tiene un papel determinante para lograr mejores niveles de desempeño y competitividad de las empresas (Ruiz \& Naranjo, 2012), la gestión de los recursos humanos dentro de las organizaciones se considera es el marco estratégico de la cultura organizacional (Gómez, Giraldo, \& Hernández, 2015)

\section{Conclusiones}

Se puede asegurar que las culturas generaran compromiso con los valores corporativos o la filosofía de gestión, lo que permitiría que los empleados trabajen por algo en lo que creen. Las culturas sirven como un sistema de control en la organización, debido a que de ellas deriban los procesos, reglas y formas que generan los patrones de comportamiento, finalmente existen estudios que aseguran que algunos tipos de culturas organizacionales están asociadas con una mayor productividad y rentabilidad (Avella, 2010; Gómez \& Prowesk, 2011; Ipinza, 2008; Martin \& Siehl, 1983). Aparentemente, las corporaciones bien administradas del mundo tienen culturas distintivas que son de alguna manera responsables de su capacidad de crear, implementar y mantener sus posiciones de liderazgo mundial (David, 2003; Feldman, 1988; 
Schwartz \& Davis, 1981). La cultura organizacional fragua el comportamiento de los empleados de las instituciones y debido a esto afecta el desempeño empresarial (Cantisano, Bañuelos, Descals, \& Amo, 2004; Hunger et al., 2007). La cultura organizacional tiene un poderoso efecto en el desempeño y eficacia a largo plazo de las organizaciones (Fralinger \& Olson, 2011; Sánchez et al., 2007). La investigación empírica ha producido una serie impresionante de hallazgos que demuestran la importancia de la cultura a la mejora del desempeño organizacional (Cameron \& Quinn, 2005).

\section{Bibliografía}

Avella, M. E. M. (2010). Relaciones entre cultura y desempeño organizacional en una muestra de empresas colombianas: Reflexiones sobre la utilización del modelo de denison. Cuadernos de administration, 23(40).

Cameron, K. S., \& Quinn, R. E. (2005). Diagnosing and changing organizational culture: Based on the competing values framework: John Wiley \& Sons.

Cantisano, G. T., Bañuelos, A. L., Descals, F. P., \& Amo, E. A. (2004). La relación de la cultura de los grupos con la satisfacción y el compromiso de sus miembros: Un análisis multigrupo. Psicothema, 16(3), 363-368.

David, R. (2003). Conceptos de administración estratégica/ frer r. David. Retrieved from

Denison, D. R. (1984). Bringing corporate culture to the bottom line. Organizational dynamics, 13(2), 5-22.

Feldman, S. P. (1988). How organizational culture can affect innovation. Organizational dynamics, 17(1), 57-68.

Fralinger, B., \& Olson, V. (2011). Organizational culture at the university level: A study using the ocai instrument. Journal of College Teaching \& Learning (TLC), 4(11).

Gómez, D. M., \& Prowesk, K. S. (2011). Características de la cultura organizacional y comunicación interna en una comercializadora de lácteos de cali. Pensamiento psicológico, 9(17), 57-68.

Gómez, H. M. S., Giraldo, C. M. Á., \& Hernández, G. C. (2015). Condiciones de causalidad entre la gestión de los recursos humanos y la cultura organizacional. Un estudio empírico en el contexto industrial colombiano. Acta Colombiana de psicología, 15(2), 119-134.

González Millán, J. J., \& Parra Penagos, C. O. (2008). Caracterización de la cultura organizacional: Clima organizacional, motivación, liderazgo y satisfacción de las pequeñas empresas del valle de sugamuxi y su incidencia en el espíritu empresarial. Pensamiento \& gestión (25), 40-57.

Hunger, J. D., Sánchez, T. L. W. M. A., Mejía, G. v. d. L. H., \& Hunger, J. D. (2007). Administración estratégica y política de negocios 10ed: Pearson Educación. 
Ipinza, F. D. A. (2008). El proceso estratégico: Un enfoque de gerencia: Centrum: Pearson Educación.

Koontz, W., Weihrich, H., \& Cannice, M. (2008). Administración: Una perspectiva global y empresarial. México: Mcgrawhill.

Martin, J., \& Siehl, C. (1983). Organizational culture and counterculture: An uneasy symbiosis. Organizational dynamics, 12(2), 52-64.

Porter, M. E., \& Kramer, M. R. (2006). Estrategia y sociedad. Harvard Business Review, 84(12), 42-56.

Robbins, S., Judge, T. A., Millett, B., \& Boyle, M. (2013). Organizational behaviour: Pearson Higher Education AU.

Ruiz, Y. B., \& Naranjo, J. C. (2012). La investigación sobre cultura organizacional en colombia: Una mirada desde la difusión en revistas científicas. Diversitas, 8(2), 285-307.

Sánchez, J. C., Lanero, A., Yurrebaso, A., \& Tejero, B. (2007). Cultura y desfases culturales de los equipos de trabajo: Implicaciones para el compromiso organizacional. Psicothema, 19(2), 218-224.

Schein, E. H. (1983). The role of the founder in creating organizational culture. Organizational dynamics, 12(1), 13-28.

Schein, E. H. (1993). On dialogue, culture, and organizational learning. Organizational dynamics, 22(2), 40-51.

Schein, E. H. (2010). Organizational culture and leadership (Vol. 2): John Wiley \& Sons.

Schwartz, H., \& Davis, S. M. (1981). Matching corporate culture and business strategy. Organizational dynamics, 10(1), 30-48.

Slocum, J. W., \& Hellriegel, D. (2009). Principles of organizational behavior: South-Western Cengage Learning.

Vargas, M. d. L. E. G., Ruiz, G. R., \& Gracia, T. J. H. (2015). Validación de un instrumento de medición que analiza la cultura organizacional desde dos perspectivas. RECAI Revista de Estudios en Contaduría, Administración e Informática, 4(10), 21-42.

Wilkins, A. L. (1983). The culture audit: A tool for understanding organizations. Organizational dynamics, 12(2), 24-38.

Zornoza, C., Porta, C. D., \& García, J. I. A. (2009). Introducción a los negocios y su gestión (8483224879). Retrieved from 